\title{
Effect of Tween Series on Growth and cis-9, trans-11 Conjugated Linoleic Acid Production of Lactobacillus acidophilus F0221 in the Presence of Bile Salts
}

\author{
Jing-Yan Li ${ }^{1}$, Lan-Wei Zhang ${ }^{1, *}$, Ming Du ${ }^{1}$, Xue Han ${ }^{1}$, Hua-Xi Yi ${ }^{1}$, Chun-Feng Guo ${ }^{2}$, \\ Ying-Chun Zhang ${ }^{1}$, Xue Luo ${ }^{1}$, Yan-He Zhang ${ }^{3}$, Yu-Juan Shan ${ }^{1}$ and Ai-Ju Hou ${ }^{1}$
}

1 School of Food Science and Engineering, Harbin Institute of Technology, Harbin 150090, China; E-Mails: jyli@hit.edu.cn (J.-Y.L.); duming121@163.com (M.D.); jiayuanhan@yahoo.com.cn (X.H.); yihx2006@yahoo.com.cn (H.-X.Y.); zyc229@163.com (Y.-C.Z.); luoxue1984@126.com (X.L.); yujuan72@163.com (Y.-J.S.); aijuhellea@yahoo.com.cn (A.-J.H.)

2 School of Food Science and Engineering, Northwest A \& F University, Yangling 712100, China; E-Mail: gcf@nwsuaf.edu.cn

3 National Key Laboratory of Veterinary Biotechnology, Harbin Veterinary Research Institute, Chinese Academy of Agricultural Sciences, Harbin 150001, China; E-Mail: yhz7606@yahoo.com.cn

* Author to whom correspondence should be addressed; E-Mail: zhanglw@hit.edu.cn; Tel./Fax: +86-451-862-829-01.

Received: 20 October 2011; in revised form: 8 November 2011 / Accepted: 16 November 2011 / Published: 8 December 2011

\begin{abstract}
Cis-9, trans-11 conjugated linoleic acid ( $c 9, t 11$ CLA) producing bacteria have attracted much attention as novel probiotics which have shown beneficial effects on host health. However, bile salts are able to inhibit bacterial growth and $c 9, t 11$ CLA production. For recovering growth and $c 9, t 11$ CLA production of Lactobacillus acidophilus F0221 in the presence of bile salts, Tween series (Tween 20, Tween 40, Tween 60 and Tween 80) were added in growth culture containing $0.3 \%$ oxgall. Results showed that the viable counts were significantly $(P<0.05)$ recovered to $8.58-8.75 \log C F U / m L$ in the presence of all Tween treatments. However, recovery of $c 9, t 11$ CLA production was only demonstrated in the presence of Tween $80(72.89 \mu \mathrm{g} / \mathrm{mL})$. Stepwise increasing oxgall in a concentrations range from $0.1 \%$ to $0.9 \%$ according to human intestinal physiological environments, Tween 80 still showed significant $(P<0.05)$ recovery ability on growth (8.91-8.04 $\log$ CFU/mL) and $c 9, t 11$ CLA $(69.22-34.27 \mu \mathrm{g} / \mathrm{mL})$ production. The effect of Tween 80 on growth and production was also investigated in the presence of different types
\end{abstract}


of bile salts (sodium salts of cholic acid (CA), deoxycholic acid (DCA), chendeoxycholic acid (CDCA), glycocholic acid (GCA) and taurocholic acid (TCA)). Results showed that Tween 80 could significantly $(P<0.05)$ recover $c 9, t 11$ CLA production in the presence of all types of bile salts, but the Tween 80 could only significantly $(P<0.05)$ recover viable counts of the strain in the presence of CA, DCA and CDCA. This recovery ability could be attributed to the protection of leakage of intracellular material. Additionally, although bile salts inhibited growth and $c 9, t 11$ CLA production by the growing cell, it promoted the $c 9$, $t 11$ CLA production by the resting cell.

Keywords: cis-9; trans-11 conjugated linoleic acid; Lactobacillus acidophilus F0221; bile salts; Tween 80 ; permeability

\section{Introduction}

Conjugated linoleic acid (CLA) represents a group of positional and geometric isomers of octadecadienoic acids with conjugated double bonds [1]. It has exhibited important physiological activities, such as having anticarcinogenic activity [2], enhancing cell immunity [3], reducing body fat content [4], inhibiting arteriosclerosis [5] and modulating the blood-glucose and insulin tolerance [6]. These beneficial activities are mainly attributed to the cis-9, trans-11 CLA ( $c 9, t 11$ CLA). The CLA cannot be synthesized in the human body [7,8], and the presence of $c 9, t 11$ CLA in human tissue (adipose, plasma and intestine) derives from food intake [9].

The main natural sources of $c 9, t 11$ CLA are meat and milk of ruminants, and the content depends on the kind of ruminants, feeding seasons and conditions [10]. Despite the higher content in ruminant products, ingestion of $c 9, t 11$ CLA by this manner is recognized as an impracticable approach to promote human health [2,11,12]. Currently, commercial $c 9, t 11$ CLA supplements are mainly synthesized by alkaline isomerization of vegetable oil, whereas the disadvantages of the alkaline isomerization are that the processes often do not produce a single $c 9, t 11$ CLA isomer at high purity [13]. Another better alternative is to convert LA to the $c 9, t 11$ CLA by bacteria in the gastrointestinal tract. Several studies have demonstrated that intake of the CLA producing bacteria such as L. rhamnosus PL60 [14], L. rhamnosus PL62 [15], and Bifidobacterium breve NCIMB 702258 [16] could improve the levels of $c 9, t 11$ CLA in intestinal lumen. However, bile salts as major antimicrobial components inhibit growth of bacteria by disruption of the permeability and integrity of the cell membrane [17,18].

Certain substances are able to protect live bacterial cells against bile salts toxicity. These antagonists include carbohydrates, surfactants and free amino acids [19,20]. They can form different complexes with the salts, and thus inhibit the toxicity to live bacterial cells. According to the report of Kimoto et al. [21], Tween series exhibited an apparent recovery ability on the growth of lactococci in the presence of bile salts. However, according to our best knowledge, the effect of Tween series on growth and $c 9, t 11$ CLA production in the presence of bile salts have not previously been reported. Therefore, the aim of this study was to investigate the bile salts toxicity on L. acidophilus F0221 growth and production of $c 9, t 11$ CLA and also determine the activity of Tween series on diminishing of bile salts toxicity. 


\section{Results}

\subsection{Effect of Oxgall on Growth and c9, t11 CLA Production}

Figure $1 \mathrm{a}$ and $1 \mathrm{~b}$ showed the ability to grow and produce $c 9, t 11$ CLA in the absence and presence of $0.3 \%$ oxgall in the LA-MRSC (MRS broth supplemented with $0.5 \mathrm{~g} / \mathrm{L} \mathrm{LA}$ and $0.5 \mathrm{~g} / \mathrm{L}$ cystein- $\mathrm{HCl}$ ) broth for the $48 \mathrm{~h}$ incubation period, respectively. During the incubation period, a tremendous increase in the absorbance value was observed in the medium without oxgall addition. The maximal cell density reached approximately 1.89 (A600 nm) after $28 \mathrm{~h}$ incubation. C9, $t 11$ CLA production was positively correlated with the cell density. The production was the highest $(101.32 \mu \mathrm{g} / \mathrm{mL})$ at the middle of stationary growth phase $(40 \mathrm{~h})$, whereas there was a slight decrease at the end of the stationary growth phase $(48 \mathrm{~h})$. When the LA-MRSC broth was supplemented with $0.3 \%$ oxgall, no detectable accumulation of $c 9, t 11$ CLA was observed in the early phase of growth $(0-12 \mathrm{~h})$. At the stationary growth phase $(40 \mathrm{~h})$, oxgall toxicity caused significant decrease of $c 9, t 11$ CLA production $(23.45 \mu \mathrm{g} / \mathrm{mL})$, which was nearly fivefold lower than in oxgall absence.

Figure 1. Time curves of growth (a) and $c 9, t 11$ CLA production (b) in LA-MRSC broth in the presence and absence of oxgall.
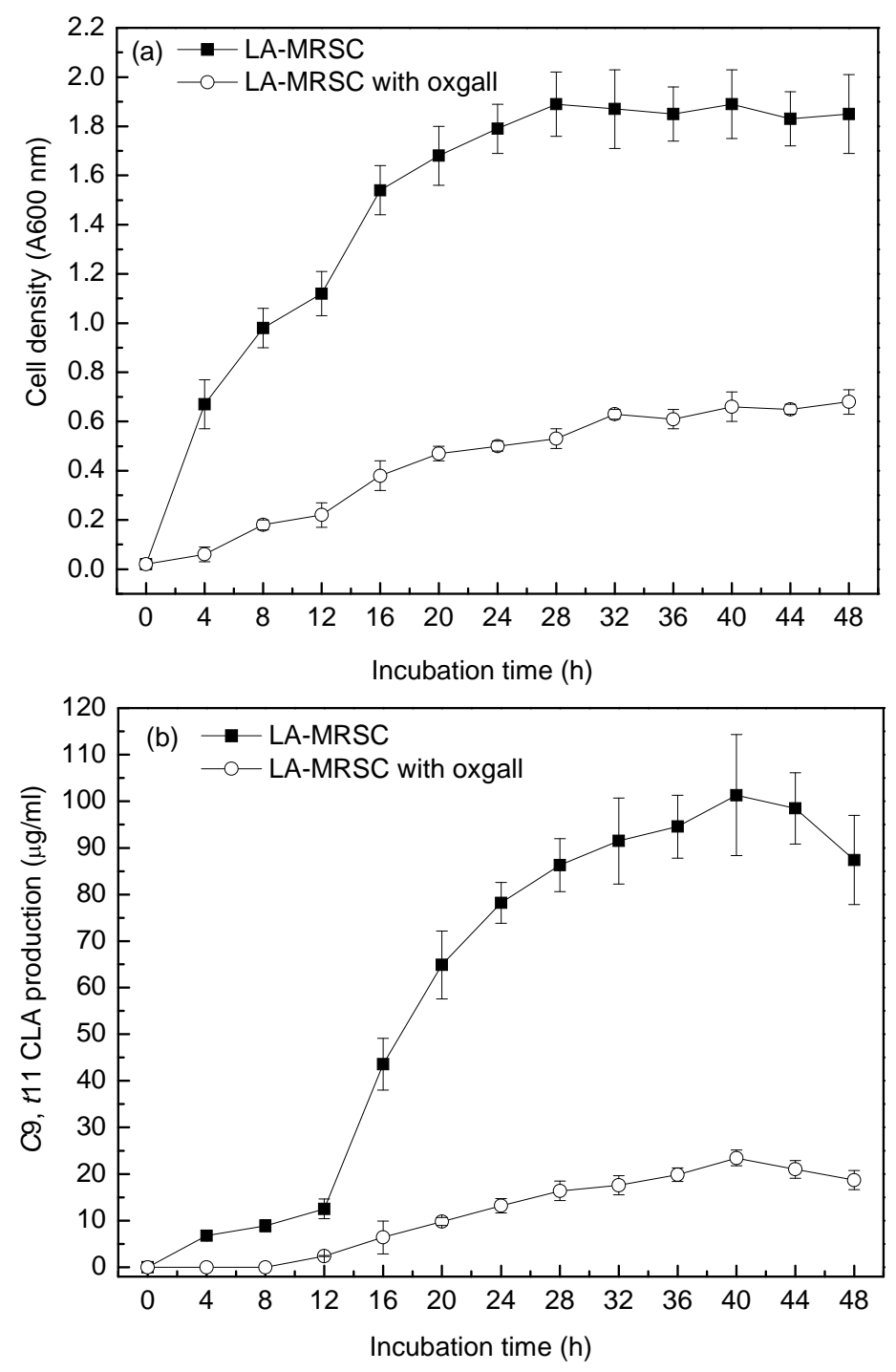


\subsection{Effect of Tween Series on Growth and c9, t11 CLA Production in the Presence of Oxgall}

Compared to those grown in LA-MRSCO broth (LA-MRSC broth supplemented with $0.3 \%$ oxgall), viable counts were significantly $(P<0.05)$ recovered to $8.58-8.75 \log \mathrm{CFU} / \mathrm{mL}$ from $7.99 \log \mathrm{CFU} / \mathrm{mL}$ in the absence of Tween by the four kinds of Tween (Figure 2). As for $c 9, t 11$ CLA production, the results indicated that only Tween 80 showed recovery ability. The production was significantly $(P<0.05)$ recovered from $22.34 \mu \mathrm{g} / \mathrm{mL}$ in the absence of Tween 80 to $72.89 \mu \mathrm{g} / \mathrm{mL}$ in the presence of the Tween 80. Although Tween 20, Tween 40 and Tween 60 were also observed to be effective in recovering cell growth, they were not able to recover the $c 9, t 11$ CLA production. Additionally, for excluding the effect of Tween 80 on $c 9, t 11$ CLA production in the absence of oxgall, cell density and $c 9$, $t 11$ CLA production were determined in LA-MRSC broth with or without Tween 80 . The results showed that Tween 80 did not significantly $(P<0.05)$ affect growth and $c 9, t 11$ CLA production (Figure 3 ).

Figure 2. Effect of Tween series on the growth and $c 9, t 11$ CLA production in the presence of $0.3 \%$ oxgall. Means with different lowercase letters (a and b) differ significantly $(P<0.05)$ in the viable counts. Means with different uppercase letters (A and B) differ significantly $(P<0.05)$ in the $c 9, t 11$ CLA production.

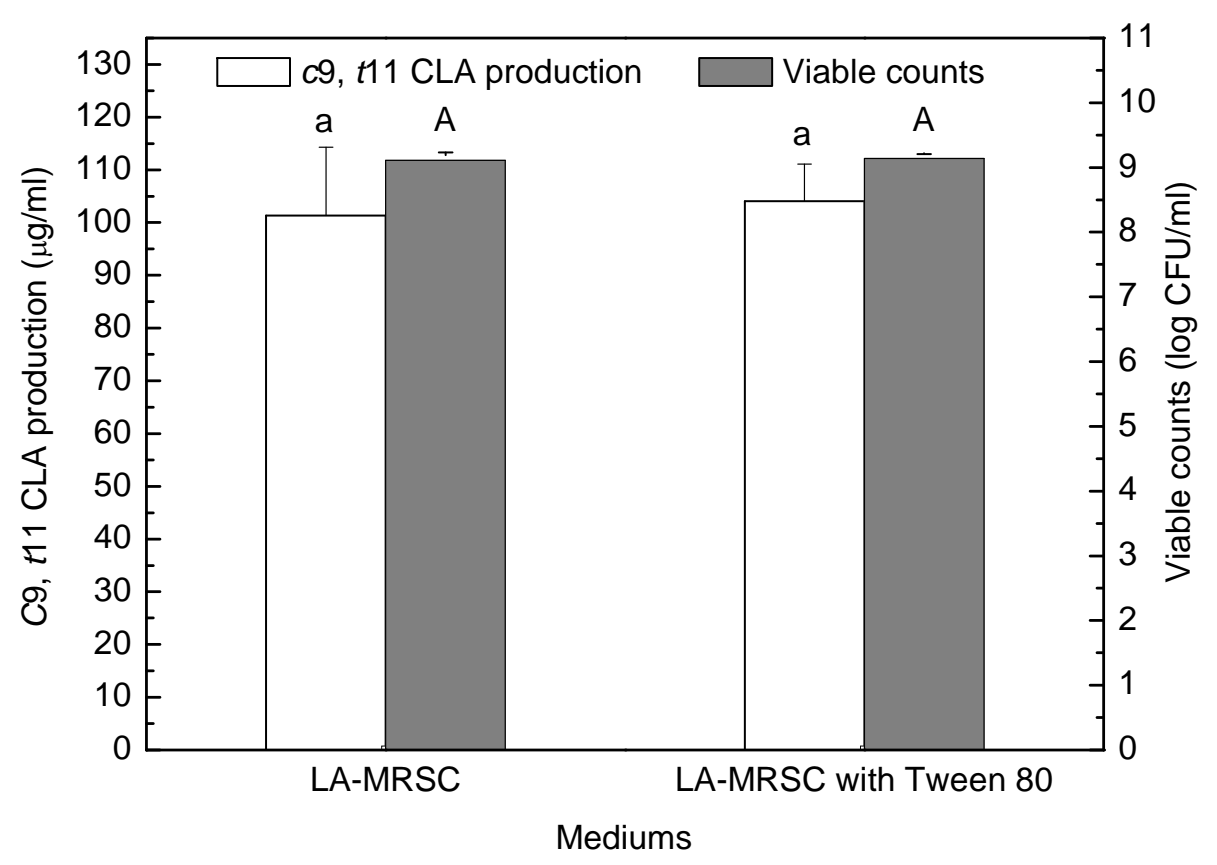


Figure 3. Effect of Tween 80 on the growth and $c 9, t 11$ CLA production in LA-MRS broth. Means with same lowercase letters does not differ significantly $(P>0.05)$ in the viable counts. Means with same uppercase letters does not differ significantly $(P>0.05)$ in the $c 9$, t11 CLA production.

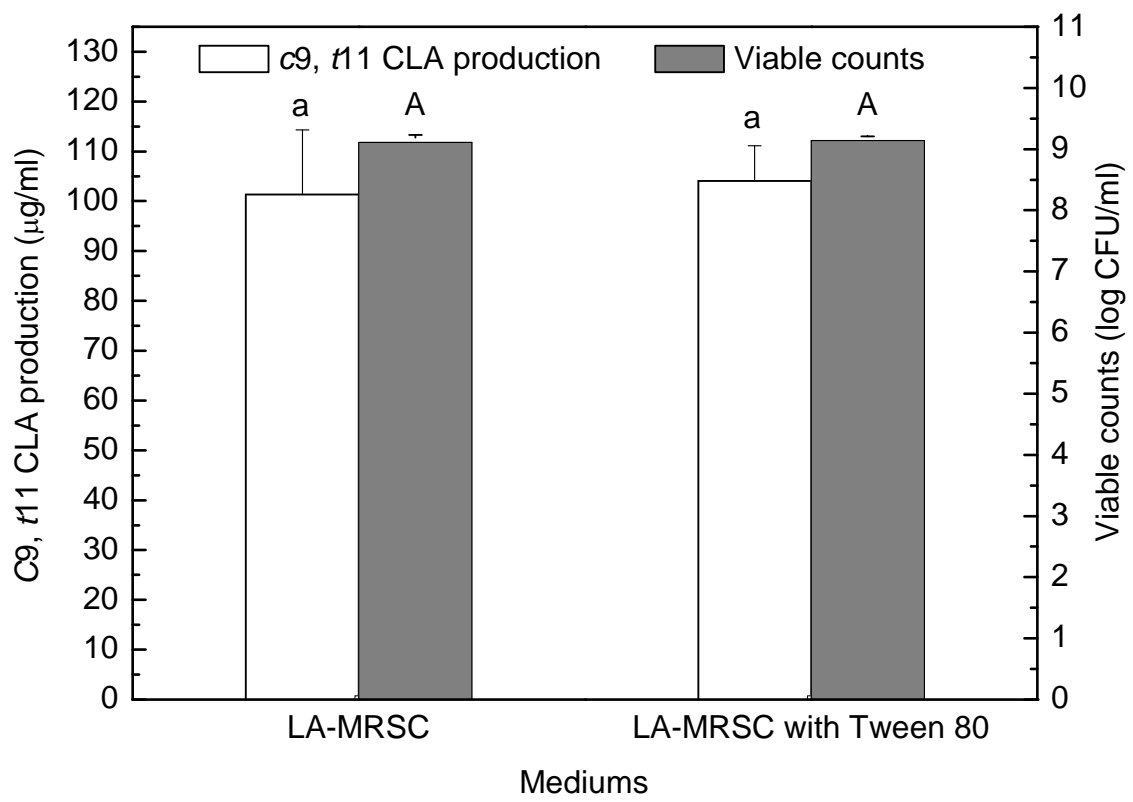

2.3. Effect of Tween 80 on Growth and c9, t11 CLA Production in the Presence of Different Concentrations of Oxgall

Stepwise increasing oxgall of concentrations ranged from $0 \%$ to $0.5 \%$ led to a gradual decrease in both viable count (from 9.11 to $7.34 \log \mathrm{CFU} / \mathrm{mL}$ ) and $c 9, t 11$ CLA production (from 101.32 to $18.09 \mu \mathrm{g} / \mathrm{mL}$, Figure $4 \mathrm{a}, \mathrm{b})$. Further increases of oxgall of concentrations to $0.7 \%$ and $0.9 \%$ resulted in death of the inoculated cells (7.04 and $6.81 \log \mathrm{CFU} / \mathrm{mL})$. However, a small amount $c 9$, $t 11$ CLA (14.61 and $10.43 \mu \mathrm{g} / \mathrm{mL}$ ) was produced in the presence of $0.7 \%$ and $0.9 \%$ oxgall.

When Tween 80 was added to the different concentrations of oxgall $(0.1 \%-0.9 \%)$ LA-MRSC broths, viable counts and $c 9, t 11$ CLA productions were significantly $(P<0.05)$ recovered to 8.91-8.04 $\log$ CFU/mL and $69.22-34.27 \mu \mathrm{g} / \mathrm{mL}$, respectively. In addition, the ability of recovery of Tween 80 on viable counts and $c 9, t 11$ CLA production in $0.1 \%-0.5 \%$ oxgall LA-MRSC broth was significantly $(P<0.05)$ higher than the counts and production in the broth supplemented with 0.7 and $0.9 \%$ oxgall.

\subsection{Effect of Tween 80 on Growth and c9, t11 CLA Production in the Presence of Different Types of} Individual Bile Salts

Figure 5a,b showed the antibacterial activity of individual bile salts against growth and $c 9$, $t 11$ CLA production. When around $7.11 \log \mathrm{CFU} / \mathrm{mL}$ cells were inoculated in TCA and GCA-LA-MRSC broths, viable counts increased to 8.41 and $8.12 \log$ CFU/mL, respectively. In CA-LA-MRSC broth, the cells showed little growth $(7.45 \log \mathrm{CFU} / \mathrm{mL})$, and in the broth containing other types of individual bile salts (DCA and CDCA), some of the inoculated cells died (6.43 and $6.19 \log \mathrm{CFU} / \mathrm{mL}$ ). As for the $c 9, t 11$ CLA production, it was decreased to 58.43 and $42.10 \mu \mathrm{g} / \mathrm{mL}$ by 
conjugated bile salts TCA and GCA, and to $30.55-12.05 \mu \mathrm{g} / \mathrm{mL}$ by deconjugated bile salts CA, DCA and CDCA.

When Tween 80 was added to the CA, DCA and CDCA-LA-MRSC broths, viable counts were significantly $(P<0.05)$ recovered to $8.19,7.86$ and $7.72 \log C F U / m L$, respectively. Tween 80 did not significantly $(P<0.05)$ recovered bacteria growth in TCA and GCA-LA-MRSC broths. When compared with $c 9, t 11$ CLA production, the Tween 80 significantly $(P<0.05)$ recovered the production to 78.33 and $74.41 \mu \mathrm{g} / \mathrm{mL}$ in the presence of conjugated bile (TCA and GCA) and to $68.85-70.74 \mu \mathrm{g} / \mathrm{mL}$ in the presence of deconjugated bile salts (CA, DCA and CDCA), respectively.

Figure 4. Effect of Tween 80 on growth (a) and $c 9, t 11$ CLA production (b) in the presence of different concentrations of oxgall. Values not sharing the same superscript are significantly different $(P<0.05)$.
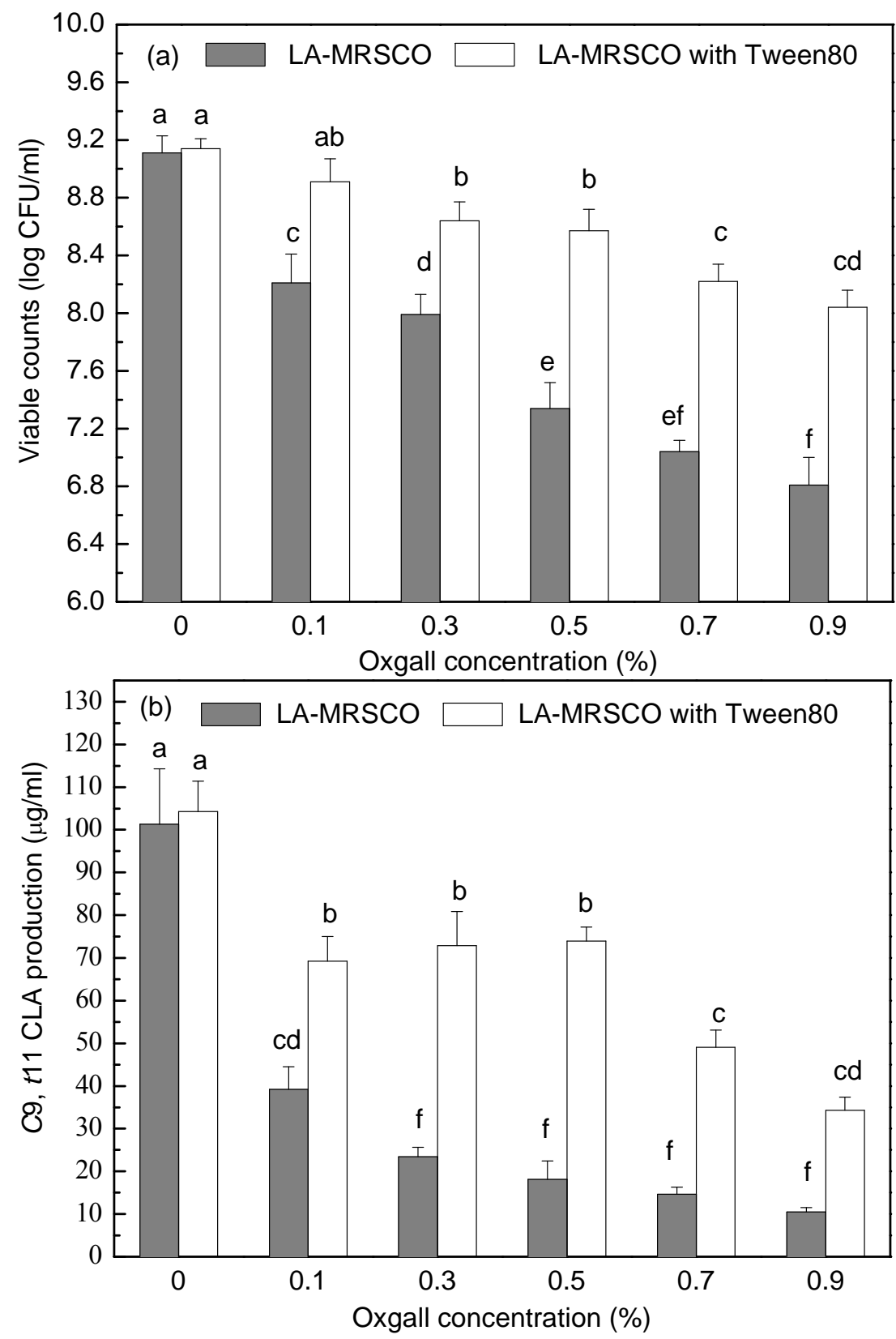
Figure 5. Effect of Tween 80 on growth (a) and $c 9, t 11$ CLA production (b) in the presence of different types of individual bile salts. Values not sharing the same superscript are significantly different $(P<0.05)$.
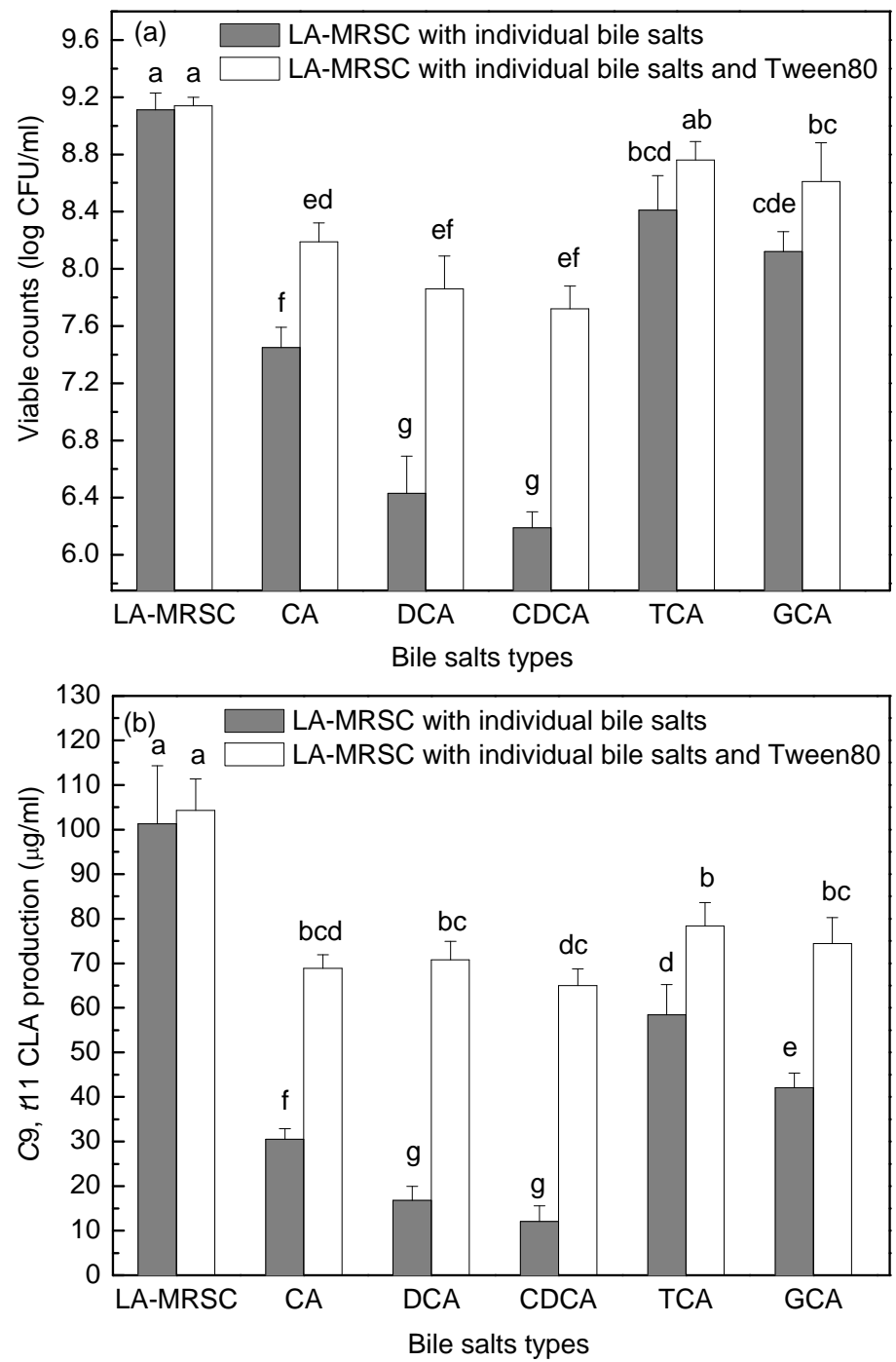

\subsection{Effect of Tween 80 on Leakage of Cellular Material in the Presence of Bile Salts by Resting Cell}

The stationary phase cells were harvested and inoculated into LA-PBSC (phosphate buffer saline (PBS) supplemented with $0.5 \mathrm{~g} / \mathrm{L} \mathrm{LA}$ and $5 \mathrm{~g} / \mathrm{L}$ cystein- $\mathrm{HCl}$ ) containing different concentrations of oxgall and different types of individual bile salts with or without Tween 80. As shown in Figure 6a,b, $0.1 \%-0.9 \%$ oxgall and $0.3 \%$ CA, DCA, CDCA and GCA resulted in leakage of intracellular material of the cell. In LA-PBSC containing $0.1 \%-0.3 \%$ oxgall and $0.3 \%$ DCA and CDCA, Tween 80 significantly $(P<0.05)$ decreased the degree of leakage of intracellular material, however, in the presence of $0.5 \%-0.9 \%$ oxgall and $0.3 \%$ CA, TCA and GCA, Tween 80 did not have a significant $(P>0.05)$ effect. 
Figure 6. Effect of Tween 80 on leakage of intracellular material in the presence of different concentrations (a) and types of individual bile salts (b).Values not sharing the same superscript are significantly different $(P<0.05)$.
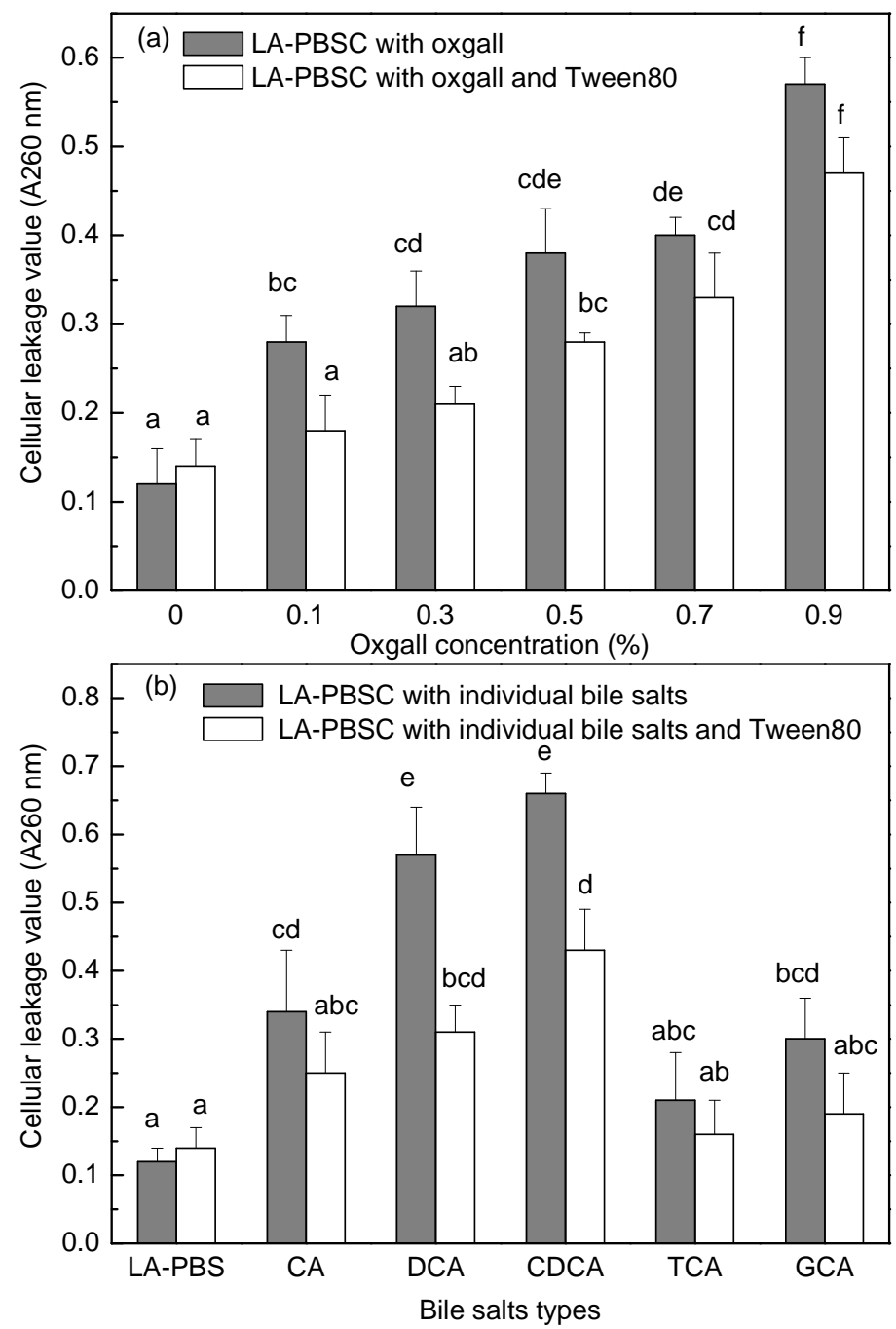

\subsection{Effect of Bile Salts on c9, t11 CLA Production by Resting Cell}

In order to investigate the bile salts effect on $c 9, t 11$ CLA production of resting cell, stationary-phase cells were harvested and incubated into the LA-PBSC containing different concentrations of oxgall $(0.1 \%-0.9 \%)$ and $0.3 \%$ different types of individual bile salts (Figure $7 \mathrm{a}, \mathrm{b})$. Results showed that the $c 9$, $t 11$ CLA production was significantly $(P<0.05)$ enhanced in the presence of $0.1 \%-0.5 \%$ oxgall compared with the control. The production reached maximum with $0.5 \%$ oxgall $(34.15 \mu \mathrm{g} / \mathrm{mL})$, which showed an approximately two-fold higher level than the control $(18.03 \mu \mathrm{g} / \mathrm{mL})$. Further increase of oxgall of concentrations to $0.7 \%$ and $0.9 \%$ did not show significantly $(P>0.05)$ increase in $c 9$, t11 CLA production.

Different types of individual bile salts also exhibited different degrees of effect on $c 9, t 11$ CLA production. Compared with the control $(18.03 \mu \mathrm{g} / \mathrm{mL})$, conjugated bile salt TCA did not significantly $(P>0.05)$ affect $c 9, t 11$ CLA production $(21.93 \mu \mathrm{g} / \mathrm{mL})$. However, other bile salts (GCA, CA, DCA and CDCA) significantly $(P<0.05)$ enhanced the production to $23.73 \mu \mathrm{g} / \mathrm{mL}, 33.42,37.98$ and $39.91 \mu \mathrm{g} / \mathrm{mL}$, respectively. 
Figure 7. Effect of different concentrations (a) and types (b) of individual bile salts on $c 9$, $t 11$ CLA production of resting cell. Values not sharing the same superscript are significantly different $(P<0.05)$.
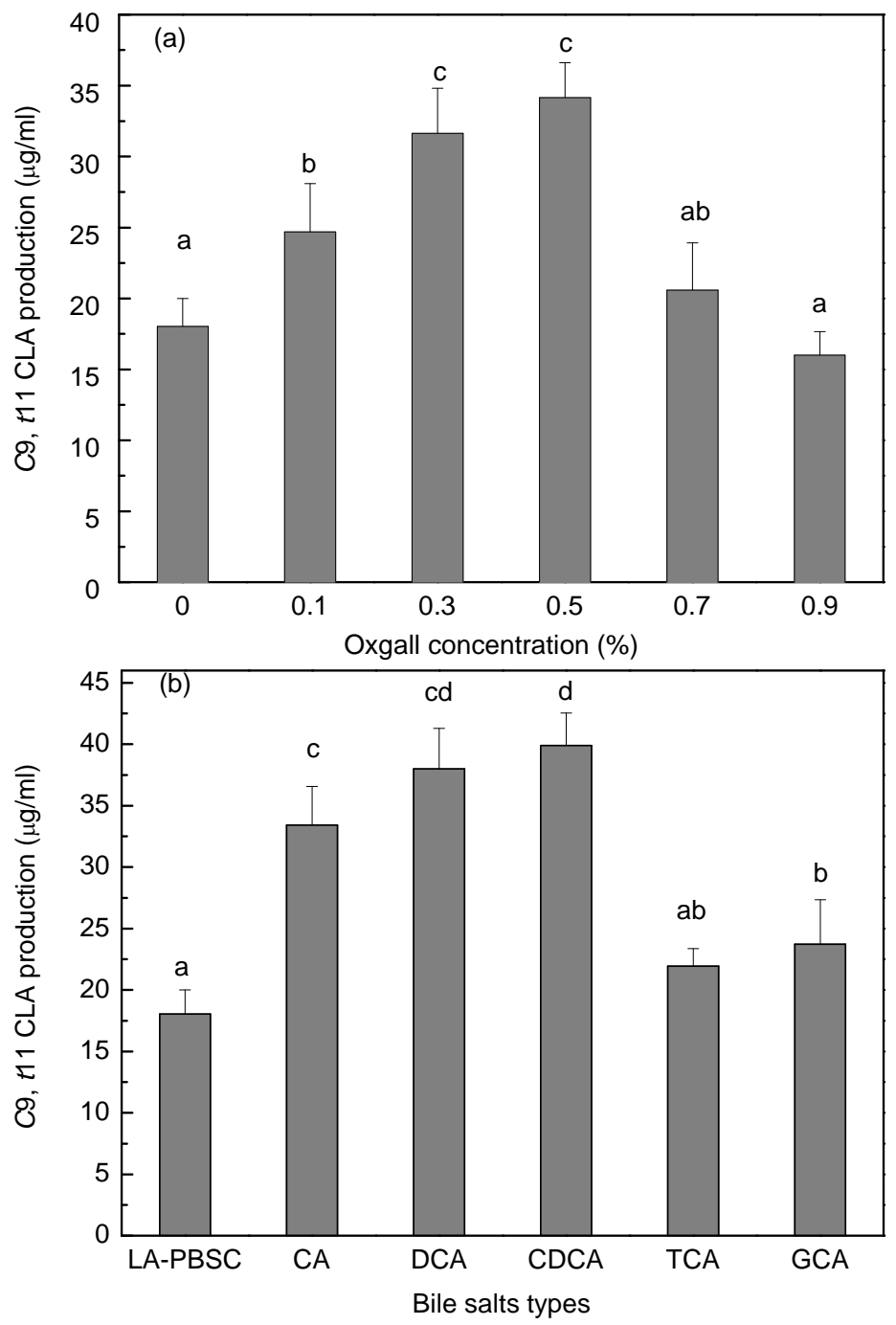

\section{Discussion}

Since bile salts are surfactant-like compounds with recognized strong antimicrobial activity, bile salts tolerance is usually considered as a prerequisite to evaluate bacteria propagation and beneficial function in the intestine. In the absence of oxgall, the maximal cell density of the strain reached $1.89(\mathrm{~A} 600 \mathrm{~nm})$ after $28 \mathrm{~h}$ incubation and the maximal $c 9, t 11 \mathrm{CLA}$ production reached $101.32 \mu \mathrm{g} / \mathrm{mL}$ at stationary growth. Because bacteria passing through the small intestine might be in a physiological state similar to the stationary phase [22], we speculated that the strain could be used as a probiotic which can exert biological activity in the human intestine.

Compared with the growth in the medium without oxgall, the absorbance of the culture had reached $0.68 \pm 0.05$ when strain was grown in the medium with $0.3 \%$ oxgall, indicating that bile salts had a significant inhibitory action on growth of the strain. Because of the strong growth inhibitory action, only very small amounts of LA could be converted to $c 9, t 11$ CLA. 
Although bile salts have been identified to have antimicrobial toxicity, the toxicity is reversible. In many instances the reversibility is modulated by the presence of certain substances such as carbon and nitrogen sources and surface-active substances [19,20]. In the present study, the use of Tween series is also effective for this objective. The order of growth recovery ability was Tween $80>$ Tween $60>$ Tween $40>$ Tween 20, and was probably due to the difference in molecular structures and hydrophilic-lipophilic balance (HLB) values of the four kinds of Tween solutions [23]. The anti-inhibitory effects of Tween series might be rationalized in terms of an ability to form micelles complexes with bile salts, thereby facilitating the removal of bile salts from intimate contact with the bacterial cell surfaces [21].

However, as for $c 9, t 11$ CLA production, only Tween 80 showed a desirable effect. This effect was probably attributed to the specific molecular structure of Tween 80 . Tween 80 contains oleic acid, which could be incorporated into bacteria cell membrane and further converted to cyclopropane fatty acid [24]. Jacques [25] has indicated that the cyclopropane fatty acid was one of the most important factors affecting cell membrane fluidity. The LA isomerase anchored to the cell membrane is responsible for the conversion of LA to $c 9, t 11$ CLA [26]. Consequently, it is likely that the increasing cell membrane fluidity results in supporting the impact of Tween 80 on the activity of LA isomerase.

Bile salts are widely distributed in the upper gastrointestinal tract and the concentration in the human intestine varies over time and with the different segments of the intestine [19,27]. In the duodenum, bile salts concentration reached approximately $0.75 \%$, and in the ileum, the concentration decreased to approximately $0.2 \%$. Bile salts at lower concentrations may disrupt membrane integrity and permeability, and at higher concentrations, the salts have induced the leakage of intracellular material and lysis [17]. In this study, the inhibition of growth and $c 9, t 11$ CLA production induced by $0.1 \%-0.5 \%$ oxgall was revovered by Tween 80 . This result indicated that Tween 80 could promote the conversion of LA to $c 9, t 11$ CLA in the ileum.

Both conjugated and deconjugated bile salts were known to inhibit the growth of intestinal bacteria, especially gram-positive bacteria [17]. In this study, the deconjugated bile salts were more toxic than the conjugated bile salts. This result was in agreement with the report of Noriega et al. [28], who interpreted that the difference in the dissociation constant of different types of bile salts might be one of the major causes. Additionally, Kurdi et al. [29] and Suskovic et al. [30] indicated that deconjugated bile salt is a hydrophobic weaker acid salt and has a higher $\mathrm{p} K_{\mathrm{a}}$ value than does the conjugated bile salt. Therefore, the relative amount of the protonated form is considerable. The protonated form of bile salts causes intracellular acidification and collapse of the proton motive force, which in turn results in inhibition of nutrient transport.

Presently, the precise mechanism for the antimicrobial activity of bile salts remains unclear. According to Taranto et al. [31], the change of chemical and physical properties of the cell membrane may account for the inhibitory activity. One of the means is by affecting the cellular permeability [21]. To investigate whether the permeability is a significant factor in recovery of cell growth and $c 9$, $t 11$ CLA production by Tween 80 , the absorbing values at $260 \mathrm{~nm}$ were determined in LA-PBSC containing different concentrations and types of bile salts with or without Tween 80 addition. The results showed that $0.1 \%-0.9 \%$ oxgall and $0.3 \%$ CA, DCA, CDCA and GCA significantly $(P<0.05)$ increased cellular permeability. In the presence of $0.1 \%-0.3 \%$ oxgall and $0.3 \%$ DCA and CDCA, Tween 80 significantly $(P<0.05)$ reduced leakage of intracellular material, but in the presence of higher concentrations $(0.5 \%-0.9 \%)$ oxgall, it showed no effect. 
Additionally, although the ability of Tween 80 to inhibit toxicity of different types of individual bile salts on cell growth appeared significantly $(P>0.05)$ different, the recovery of $c 9, t 11$ CLA production was nearly consistent. The result is inconsistent with the report of Kim et al. [26], who indicated that $c 9, t 11$ CLA production was highly related to the viable counts. This leads us to speculate whether bile salt affect the $c 9, t 11$ CLA production on the resting cell. Therefore, we determined the effect of bile salts on $c 9, t 11$ CLA production by the resting cell. The result was consistent with our speculation that bile salts play a positive effect on $c 9, t 11$ CLA production. However, this phenomenon was only suitable for the resting cell, but not for the growing cell, since the toxicity of bile salts inhibited cell growth in growth medium and therefore decreased the amounts of resting cell.

It has been reported that bile salts can enhance the activity of certain endoenzymes such $\beta$-galactosidase and $\beta$-glucuronidase by increasing cell membrane permeability $[32,33]$. Additionally, Sanchez et al. [34] reported that bile salts could result in folds of the bacterial membrane protein, and then alter conformation of proteins. Linoleic acid isomerase is a membrane-bound enzyme, whose activity might be alterated by these approaches.

\section{Experimental Section}

\subsection{Strain Isolation and Maintenance}

Freshly collected human fecal sample was diluted 10-fold in anaerobic buffered peptone water containing $0.5 \mathrm{~g} / \mathrm{L}$ cystein-HCl (Sigma Chemical Co., St. Louis, MO, USA), and spread on MRS agar plates [35] supplemented with $0.5 \mathrm{~g} / \mathrm{L}$ cystein- $\mathrm{HCl}$. The plates were incubated at $37{ }^{\circ} \mathrm{C}$ for $48 \mathrm{~h}$ in an anaerobic incubation system (model 1029, Forma Scientific Inc., Marietta, OH, USA) with an atmosphere of $85 \% \mathrm{~N}_{2}, 10 \% \mathrm{H}_{2}$ and $5 \% \mathrm{CO}_{2}$. Pure colonies were collected and a $c 9, t 11$ CLA producing strain was screened out according to the method described by Chung et al. [36]. The strain was identified as L. acidophilus F0221 based on carbohydrate fermentation patterns by using API 50 CHL test kit (Biomérieux, Marcy-l'Etoile, France) with a computer-aided identification program (version 4.0, Biomérieux). The strain was maintained and sub-cultured in MRSC broth. Prior to assay, the strain was serially transferred three times at $37^{\circ} \mathrm{C}$ for $18 \mathrm{~h}$.

\subsection{Bacteria Enumeration and Cell Density Measurement}

The numbers of L. acidophilus F0221 in the experimental samples were determined using the spread plate method. The culture was serially diluted in $0.5 \% \mathrm{NaCl}$ solution, appropriate dilutions were spread on MRSC agar plates incubated at $37{ }^{\circ} \mathrm{C}$ for $48 \mathrm{~h}$ under anaerobic conditions. Viable counts were described as $\log \mathrm{CFU} / \mathrm{mL}$. Cell density was monitored by reading the absorbance at $600 \mathrm{~nm}$ (A600 $\mathrm{nm}$ ) using a spectrophotometer (Ultrospec 1100 pro, Amersham Biosciences, UK).

\subsection{Fatty Acid Analysis}

The culture was inoculated into LA-MRSC broth and incubated at $37{ }^{\circ} \mathrm{C}$ for $48 \mathrm{~h}$ under anaerobic conditions. Fatty acid in culture $(1 \mathrm{~mL})$ was extracted with $6 \mathrm{~mL}$ of chloroform: methanol $(2: 1, \mathrm{v} / \mathrm{v})$. Followed by $30 \mathrm{~s}$ vigorously shaking, the mixture was centrifuged $\left(5000 \mathrm{~g}, 10 \mathrm{~min}, 4{ }^{\circ} \mathrm{C}\right)$. The chloroform phase was dried under a nitrogen flow in a water bath at $40{ }^{\circ} \mathrm{C}$. The lipid residue was 
immediately methylated with $1 \mathrm{~mL}$ of $1 \mathrm{M}$ sulfuric acid in methanol at $60{ }^{\circ} \mathrm{C}$ for $30 \mathrm{~min}$. After cooling, the methylated sample was mixed with $1 \mathrm{~mL} n$-hexane, shaken for $30 \mathrm{~s}$, and was then centrifuged $\left(5000 \mathrm{~g}, 5 \mathrm{~min}, 4^{\circ} \mathrm{C}\right)$. The $n$-hexane layer was dehydrated with anhydrous sodium sulfate and analyzed for the $c 9, t 11$ CLA isomers.

The $c 9, t 11$ CLA isomers was analyzed using an Agilent 7890 gas chromatograph equipped with a FID detector and a fused silica capillary column HP-88 $(100 \mathrm{~m} \times 0.25 \mathrm{~mm}$ i.d., $0.2 \mu \mathrm{m}$ film thickness, Agilent Technologies, Santa Clara, CA, USA). Heptadecanoic acid was added as the internal standard prior to the fatty acid extraction to determine the recovery rate. $c 9, t 11$ CLA was used as standard to identify and quantify the $c 9, t 11$ CLA isomer by comparison with the retention time and peak areas, and the amount in each sample was expressed as $\mu \mathrm{g} / \mathrm{mL}$. Figure 8 shows the fatty acid peak of C17:0, $c 9, t 11$ CLA and $t 10, c 12$ CLA standards (a), LA-MRSC broth (b) and $c 9, t 11$ CLA produced by L. acidophilus F0221 in LA-MRSC broth (c).

Figure 8. GC chromatogram for the fatty acid compositions. (a) C17:0, $c 9, t 11$ CLA and t10, c12 CLA standards; (b) LA-MRSC broth; (c) incubation of L. acidophilus F0221 in LA-MRSC broth.
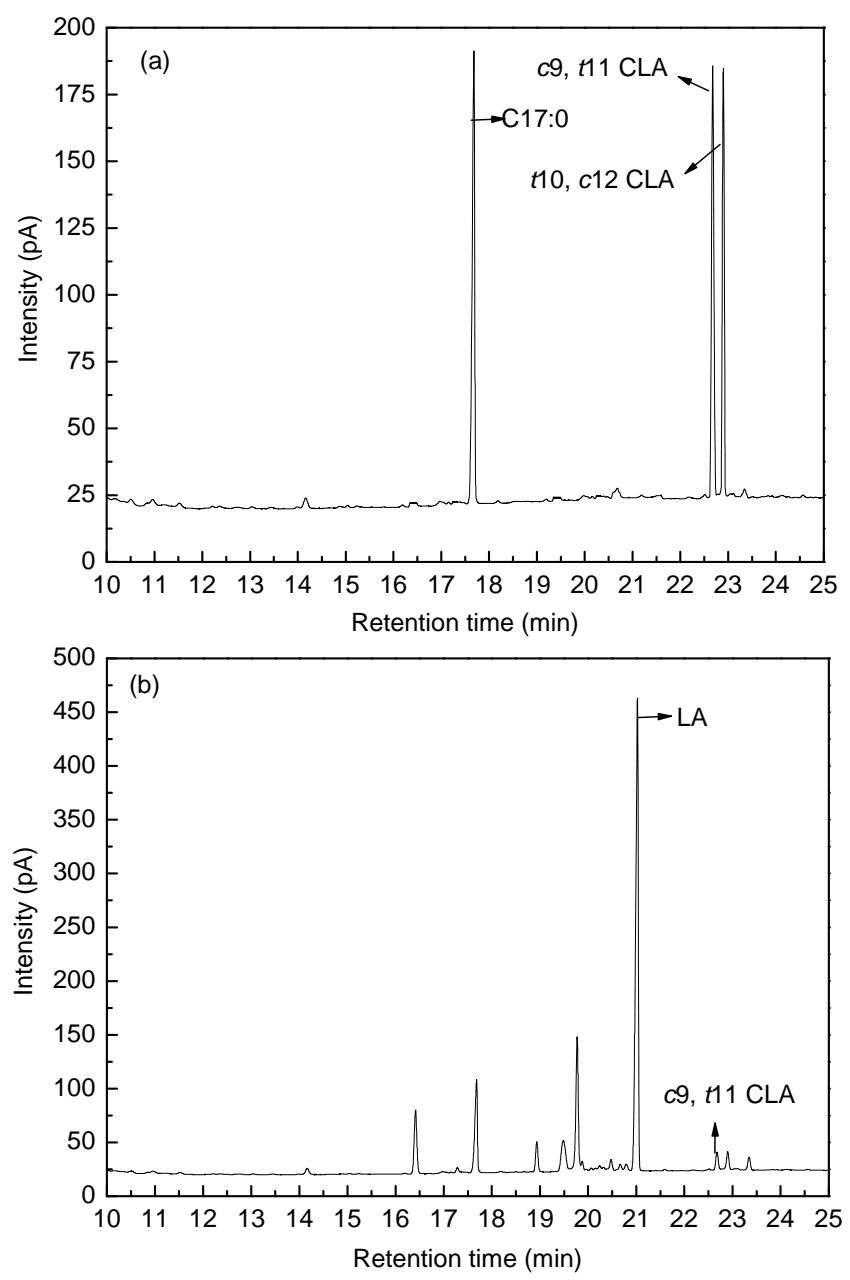
Figure 8. Cont.

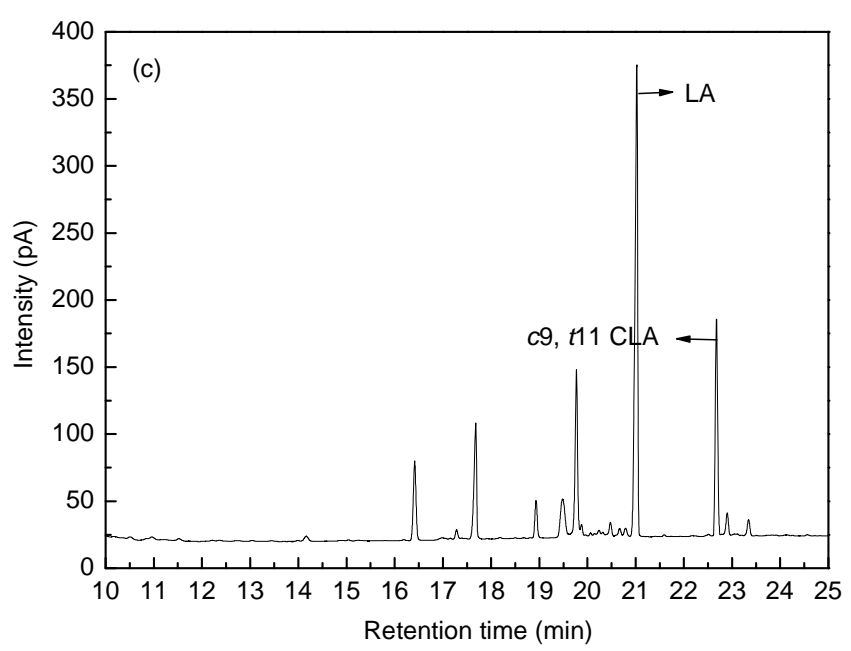

\subsection{Cell Growth and c9, t11 CLA Production in the Presence of Oxgall}

The overnight culture (1\%) was inoculated into LA-MRSC broth supplemented with $0.3 \%$ oxgall and incubated under anaerobic conditions at $37{ }^{\circ} \mathrm{C}$. Cell density and $c 9, t 11$ CLA production were monitored during the incubation period of $48 \mathrm{~h}$. LA-MRSC broth without oxgall was used as a control.

\subsection{Effect of Tween Series on Cell Growth and c9, t11 CLA Production in the Presence of Oxgall}

The overnight culture (1\%) was inoculated into LA-MRSCO broth supplemented with 1.5\% (w/v) different Tween (Tween 20, Tween 40, Tween 60 and Tween 80). The culture was incubated under anaerobic conditions at $37{ }^{\circ} \mathrm{C}$ for $40 \mathrm{~h}$, viable counts and $c 9, t 11$ CLA production were determined after incubation. LA-MRSCO broth without Tween was used as a control.

4.6. Effect of Tween 80 on Cell Growth and c9, t11 CLA Production in the Presence of Different Concentrations and Types of Individual Bile Salts

The overnight culture (1\%) was inoculated into LA-MRSC broth supplemented 1.5\% (w/v) Tween 80 , different concentrations of oxgall $(0 \%, 0.1 \%, 0.3 \%, 0.5 \%, 0.7 \%$ and $0.9 \%(\mathrm{w} / \mathrm{v}))$ and $0.3 \%$ $(\mathrm{w} / \mathrm{v})$ different types of individual bile salts (CA, DCA, CDCA, GCA and TCA), respectively. The culture was incubated at $37^{\circ} \mathrm{C}$ under anaerobic conditions. After 40 -h incubation, viable counts and $c 9$, $t 11$ CLA productions were determined. In each experiment, the medium without Tween 80 was used as control.

\subsection{Effect of Tween 80 on Leakage of Intracellular Material in the Presence of Bile Salts by Resting Cell}

Leakage of intracellular material of the strain was determined according to the method of Kimeto et al. [21]. The overnight culture $(0.5 \mathrm{~mL})$ was inoculated into $50 \mathrm{~mL}$ LA-MRSC broth and incubated at $37^{\circ} \mathrm{C}$ for $40 \mathrm{~h}$ under anaerobic conditions. Resting cell was harvested by centrifugation $\left(12,000 \mathrm{~g}, 15 \mathrm{~min}, 4{ }^{\circ} \mathrm{C}\right.$ ), washed twice with phosphate buffer saline (PBS), and suspended in $10 \mathrm{~mL}$ of LA-PBSC supplemented with Tween 80 and different concentrations of oxgall $(0.1 \%, 0.3 \%, 0.5 \%$, 
$0.7 \%$ and $0.9 \%, \mathrm{w} / \mathrm{v})$ or $0.3 \%(\mathrm{w} / \mathrm{v})$ concentration of different types of individual bile salts (CA, DCA, CDCA, TCA and GCA). The media with Tween 80 was used to evaluate the effect of Tween 80 on leakage of intracellular material of the strain in the presence of bile salts, and the media without Tween 80 was used as control.

The culture was placed in a shaking water bath and incubated at $37{ }^{\circ} \mathrm{C}$ for $2 \mathrm{~h}$. The suspensions were centrifuged $\left(12,000 \mathrm{~g}\right.$ for $15 \mathrm{~min}$ at $\left.4{ }^{\circ} \mathrm{C}\right)$ and the leakage of cellular material of the cell was determined by measuring the supernatants as absorbance at $260 \mathrm{~nm}$ (A260 nm) with a Spectronic 20 spectrophotometer (Bausch and Lomb, Rochester, NY, USA) against a control.

\subsection{Effect of Bile Salts on c9, t11 CLA Production by Resting Cell}

Cell suspensions with different concentrations oxgall and different types of individual bile salts were prepared as described above, and each LA-PBSC without bile salts was used as a control. Cell suspensions were placed in a shaking water bath and incubated at $37^{\circ} \mathrm{C}$ for $2 \mathrm{~h}$. All suspensions were collected for analyzing $c 9, t 11$ CLA production as described previously.

\subsection{Statistical Analysis}

Statistical analyses were performed using SPSS 15.0 software (SPSS Inc., Chicago, IL, USA). All experiments were performed in duplicate and repeated three times. Data are presented as the mean \pm SD. Significant differences between treatments were tested by ANOVA followed by Tukey's test with a level of significance of $\alpha=0.05$.

\section{Conclusions}

In conclusion, the inhibitory effect of bile salts on growth and $c 9, t 11$ CLA production of was reversed by Tween 80 . The recovery ability was also effective in the presence of $0.1 \%-0.9 \%$ oxgall and $0.3 \%$ deconjugated bile salts and conjugated bile salts. This phenomenon is partially attributed to the protection of Tween 80 on leakage of intracellular material. However, all the results in this study were obtained in vitro, therefore further in vivo experiments will be required. Such work is being performed at our laboratory.

\section{Acknowledgments}

This work was financially supported by the National Natural Science Foundation of China (30871816/C120108) and R\&D Program Grants from Educational Committee of Heilongjiang Province (1055GZD03-2004) and National High-Tech R\&D Program Grants from the Ministry of Science and Technology of the People's Republic of China (2011AA100805-1).

\section{References}

1. Ha, Y.L.; Grimm, N.K.; Pariza, M.W. Anticarcinogens from fried ground beef: heat-altered derivatives of linoleic acid. Carcinogenesis 1987, 8, 1881-1887. 
2. Ip, C.; Singh, M.; Thompson, H.J.; Scimeca, J.A. Conjugated linoleic acid suppresses mammary carcinogenesis and proliferative activity of the mammary-gland in the rat. Cancer Res. 1994, 54, 1212-1215.

3. Jaudszus, A.; Foerster, M.; Kroegel, C.; Wolf, I.; Jahreis, G. Cis-9, Trans-11-CLA exerts anti-inflammatory effects in human bronchial epithelial cells and eosinophils: Comparison to Trans-10, Cis-12-CLA and to linoleic acid. Biochim. Biophys. Acta Mol. Cell Biol. Lipids 2005, 1737, 111-118.

4. Racine, N.M.; Watras, A.C.; Carrel, A.L.; Allen, D.B.; McVean, J.J.; Clark, R.R.; O’Brien, A. R.; O'Shea, M.; Scott, C.E.; Schoeller, D.A. Effect of conjugated linoleic acid on body fat accretion in overweight or obese children. Am. J. Clin. Nutr. 2010, 91, 1157-1164.

5. Smit, L.A.; Baylin, A.; Campos, H. Conjugated linoleic acid in adipose tissue and risk of myocardial infarction. Am. J. Clin. Nutr. 2010, 92, 34-40.

6. Ryder, J.W.; Portocarrero, C.P.; Song, X.M.; Cui, L.; Yu, M.; Combatsiaris, T.; Galuska, D.; Bauman, D.E.; Barbano, D.M.; Charron, M.J.; et al. Isomer-specific antidiabetic properties of conjugated linoleic acid. Improved glucose tolerance, skeletal muscle insulin action, and UCP-2 gene expression. Diabetes 2001, 50, 1149-1157.

7. Collomb, M.; Schmid, A.; Sieber, R.; Wechsler, D.; Ryhanen, E.L. Conjugated linoleic acids in milk fat: Variation and physiological effects. Int. Dairy J. 2006, 16, 1347-1361.

8. McGuire, M.K.; Park, Y.; Behre, R.A.; Harrison, L.Y.; Shultz, T.D.; McGuire, M.A. Conjugated linoleic acid concentrations of human milk and infant formula. Nutr. Res. 1997, 17, 1277-1283.

9. Jiang, J.; Wolk, A.; Vessby, B. Relation between the intake of milk fat and the occurrence of conjugated linoleic acid in human adipose tissue. Am. J. Clin. Nutr. 1999, 70, 21-27.

10. Chin, S.F.; Liu, W.; Storkson, J.M.; Ha, Y.L.; Pariza, M.W. Dietary sources of conjugated dienoic isomers of linoleic acid, a newly recognized class of anticarcinogens. J. Food Compos. Anal. 1992 , 5, 185-197.

11. Sieber, R.; Collomb, M.; Aeschlimann, A.; Jelen, P.; Eyer, H. Impact of microbial cultures on conjugated linoleic acid in dairy products a review. Int. Dairy J. 2004, 14, 1-15.

12. Albers, R.; van der Wielen, R.P.J.; Brink, E.J.; Hendriks, H.F.J.; Dorovska-Taran, V.N.; Mohede, I.C.M. Effects of cis-9, trans-11 and trans-10, cis-12 conjugated linoleic acid (CLA) isomers on immune function in healthy men. Eur. J. Clin. Nutr. 2003, 57, 595-603.

13. Berdeaux, O.; Voinot, L.; Angioni, E.; Juaneda, P.; Sebedio, J.L. A simple method of preparation of methyl trans-10, cis-12- and cis-9, trans-11-octadecadienoates from methyl linoleate. J. Am. Oil. Chem. Soc. 1998, 75, 1749-1755.

14. Lee, H.Y.; Park, J.H.; Seok, S.H.; Baek, M.W.; Kim, D.J.; Lee, K.E.; Paek, K.S.; Lee, Y. Human originated bacteria, Lactobacillus rhamnosus PL60, produce conjugated linoleic acid and show anti-obesity effects in diet-induced obese mice. Biochim. Biophys. Acta Mol. Cell Biol. Lipids 2006, 1761, 736-744.

15. Lee, K.; Paek, K.; Lee, H.Y.; Park, J.H.; Lee, Y. Antiobesity effect of trans-10, cis-12-conjugated linoleic acid-producing Lactobacillus plantarum PL62 on diet-induced obese mice. J. Appl. Microbiol. 2007, 103, 1140-1146.

16. Wall, R.; Ross, R.P.; Shanahan, F.; O’Mahony, L.; O’Mahony, C.; Coakley, M.; Hart, O.; Lawlor, P.; Quigley, E.M.; Kiely, B.; et al. Metabolic activity of the enteric microbiota influences 
the fatty acid composition of murine and porcine liver and adipose tissues. Am. J. Clin. Nutr. 2009, 89, 1393-1401.

17. Begley, M.; Gahan, C.G.M.; Hill, C. The interaction between bacteria and bile. FEMS Microbiol. Rev. 2005, 29, 625-651.

18. Noh, D.O.; Gilliland, S.E. Influence of bile on cellular integrity and $\beta$-galactosidase activity of Lactobacillus acidophilus. J. Dairy Sci. 1993, 76, 1253-1259.

19. Noriega, L.; Gueimonde, M.; Sanchez, B.; Margolles, A.; de los Reyes-Gavilan, C.G. Effect of the adaptation to high bile salts concentrations on glycosidic activity, survival at low $\mathrm{pH}$ and cross-resistance to bile salts in Bifidobacterium. Int. J. Food Microbiol. 2004, 94, 79-86.

20. Patel, H.M.; Pandiella, S.S.; Wang, R.H.; Webb, C. Influence of malt, wheat, and barley extracts on the bile tolerance of selected strains of lactobacilli. Food Microbiol. 2004, 21, 83-89.

21. Kimoto, H.; Ohmomo. S.; Okamoto, T. Enhancement of bile tolerance in lactococci by Tween 80 . J. Appl. Microbiol. 2002, 92, 41-46.

22. Lundeen, S.G.; Savage, D.C. Characterization and purification of bile salt hydrolase from Lactobacillus sp. Strain 100-100. J. Bacteriol. 1990, 172, 4171-4177.

23. Cheng, Y.Y.; Yang, J.P. Solubilization of non-steroidal anti-inflammatory drugs in the presence of Tween series surfactants. Phys. Chem. Liq. 2006, 44, 249-256.

24. Partanen, L.; Marttinen, N.; Alatossava, T. Fats and fatty acids as growth factors for Lactobacillus delbrueckii. Syst. Appl. Microbiol. 2001, 24, 500-506.

25. Jacques, N.A. Studies on cyclopropane fatty acid synthesis: Correlation between the state of reduction of respiratory components and the accumulation of methylene hexadecanoic acid by Pseudomonas denitrificans. Biochim. Biophys. Acta 1981, 665, 270-282.

26. Kim, Y.J.; Liu, R.H.; Bond, D.R.; Russell, J.B.; Effect of linoleic acid concentration on conjugated linoleic acid production by Butyrivibrio fibrisolvens A38. Appl. Environ. Microbiol. 2000, 66, 5226-5230.

27. Marteau, P.; Minekus, M.; Havenaar, R.; Veld, J. Survival of lactic acid bacteria in a dynamic model of the stomach and small intestine: Validation and the effects of bile. J. Dairy Sci. 1997, 80, 1031-1037.

28. Noriega, L.; Cuevas, I.; Margolles, A.; de los Reyes-Gavilan, C.G. Deconjugation and bile salts hydrolase activity by Bifidobacterium strains with acquired resistance to bile. Int. Dairy J. 2006, $16,850-855$.

29. Kurdi, P.; Kawanishi, K.; Mizutani, K.; Yokota, A. Mechanism of growth inhibition by free bile acids in Lactobacilli and Bifidobacteria. J. Bacteriol. 2006, 188, 1979-1986.

30. Suskovic, J.; Kos, B.; Matosic, S.; Besendorfer, V. The effect of bile salts on survival and morphology of a potential probiotic strain Lactobacillus acidophilus M92. World J. Mircobiol. Biotechnol. 2000, 16, 673-678.

31. Taranto, M.P.; Murga, M.L.F.; Lorca, G.; de Valdez, G.F. Bile salts and cholesterol induce changes in the lipid cell membrane of Lactobacillus reuteri. J. Appl. Microbiol. 2003, 95, 86-91.

32. Fujisawa, T.; Mori, M. Influence of bile salts on $\beta$-glucuronidase activity of intestinal bacteria. Lett. Appl. Microbiol. 1996, 22, 271-274.

33. Noh, D.O.; Gilliland, S.E. Influence of bile on $\beta$-galactosidase activity of component species of yogurt starter cultures. J. Dairy Sci. 1994, 77, 3532-3537. 
34. Sanchez, B.; de los Reyes-Gavilan, C.G.; Margolles, A. The F1F0-ATPase of Bifidobacterium animalis is involved in bile tolerance. Environ. Microbiol. 2006, 8, 1825-1833.

35. de Man, J.C.; Rogosa, M.; Sharpe, M.E. A medium for the cultivation of lactobacilli. J. Appl. Bacteriol. 1960, 23, 130-135.

36. Chung, S.H.; Kim, I.H.; Park, H.G.; Kang, H.S.; Yoon, C.S.; Jeong, H.Y.; Choi, N.J.; Kwon, E.G.; Kim, Y.J. Synthesis of conjugated linoleic acid by human-derived Bifidobacterium breve LMC 017: Utilization as a functional starter culture for milk fermentation. J. Agric. Food Chem. 2008, $56,3311-3316$.

(C) 2011 by the authors; licensee MDPI, Basel, Switzerland. This article is an open access article distributed under the terms and conditions of the Creative Commons Attribution license (http://creativecommons.org/licenses/by/3.0/). 